\title{
ON THE DERIVATION OF THE HARTREE-FOCK EQUATIONS
}

\author{
By \\ I. MAYER \\ CENTRAL RESEARCH INSTITUTE FOR CHEMISTRY OF THE \\ HUNGARIAN ACADEMY OF SCIENCES, BUDAPEST
}

(Acta Phys. Hung. 30, 373, 1971)

A misprint (incorrect sign) which distorts the meaning has been found in Eq. (5). Eq. (5) should read

$$
E_{2}=H_{00}+\frac{1}{2}\left(H_{00}-H_{11}\right)\left[\sqrt{1+\frac{4\left|H_{01}\right|^{2}}{\left(H_{00}-H_{11}\right)^{2}}}-1\right] .
$$

\section{TIRED LIGHT AND THE "MISSING MASS" PROBLEM}

\author{
By \\ W. Yourgrau and J. F. Woodward \\ FOUNDATION OF PHYSICS, UNIVERSITY OF DENVER \\ DENVER, COLORADO 80210, USA
}

(Acta Phys. Hung. 30, 325, 1971)

Lines 10-13 of Section IV (page 327) should be replaced by:"finite rest mass. In order to obtain equation (2) one may modify the electromagnetic equations by taking a potential $(\Phi)$ of the form

$$
\Phi \sim e^{-\mu r} / r
$$

for the electrostatic and monopole magnetostatic fields. Such a substitution yields immediately a Poynting vector of the form"... 